\title{
Special collections as a catalyst for flexible pedagogical approaches: three case studies
}

\author{
Maria Kukhareva \\ University of Bedfordshire \\ Anne Lawrence \\ University of Bedfordshire \\ Katherine Koulle \\ UCL Institute of Education \\ Nazlin Bhimani \\ UCL Institute of Education
}

\section{Abstract}

University special collections are increasingly being recognised as a valuable pedagogical resource in higher education teaching and learning. The value of historical artefacts as a cross-disciplinary tool to promote higher order thinking processes such as criticality, questioning and narrative construction is well-established in the museum education literature and is gaining increasing attention in teaching and learning development. In this paper, we present three case studies in which we explore the application of special collections in a range of learning development contexts in order to help students engage with their discipline and discipline-specific higher order skills. Our case studies are explorative in the sense of 'trialling' the use of historical artefacts in the classroom, to inform our next steps and the development of our method. We conclude with our reflections on the process and outcomes of our explorations in order to inform our practice and that of other educators looking to apply this method.

Keywords: flexible pedagogies; special collections; historical artefacts; museum education; academic writing; information literacy; narrative enquiry. 


\section{Introduction}

Flexible pedagogical approaches can take different forms. In this paper, we present three case studies that advocate the broader use of university special collections as a flexible pedagogical resource aimed at enhancing students' learning and development.

The case studies are 'works in progress' - elements of pedagogical practice that act as an exploration of the application of special collections. We are on a journey of discovery, continually refining this method within teaching and learning development. The origin of this article lies in an exploratory workshop for teaching staff which we facilitated at Bedfordshire. Grounded in object-based learning, visual literacy and museum education, the workshop provided a space to explore the versatility of special collection artefacts for teaching subject-specific material and relevant academic competencies. High levels of interest and positive feedback from the participants encouraged us to develop the concept further, across two institutions. Here we share insights from this exploration, in particular around the design and the implementation of the method. It is important to clarify that, rather than evaluating a completed research project, we present our paper from a 'practitioner angle', focusing on our continuing explorations of developing and refining a new teaching method from our own observations, as our method, and student feedback.

The three case studies focus on our engagement with students across three disciplines (Business Studies, Education Studies, Music Education), and three levels of study (foundation, final year undergraduate, postgraduate), and are written from three different practitioner perspectives (Educational Developer, Librarian, Academic Writing Senior Teaching Fellow). This variation provided us with valuable insights in terms of further adapting the method. Our main aim is to explore and develop a teaching method which could help students engage with their discipline or discipline-specific skills through an unexpected, possibly surprising, medium: historical images and objects. By inviting our students to 'trial' the use of the artefacts in the classroom, we aimed to acquire information to inform our next steps. Further explanation of this process is discussed in our method section below.

The reader will notice that our models share a common thread: authenticity of the artefacts as a catalyst for students' curiosity and engagement, criticality, argument construction, 
reflexivity and own subjectivity, and transferability of thinking. Each case study, however, has its own 'leading' focus. The first focusses on questioning as a way to own positionality and narrative enquiry, the second on critical analysis and information literacy, and the third explores criticality in academic writing. We have deliberately preserved the variations in underpinning approaches to be helpful to a broad range of educators.

\section{Special collections across and beyond disciplines}

Museum and university special collections are increasingly looked upon with interest by higher education educators as a helpful, and perhaps, surprising teaching resource. There seems to be a 'coming together' of museum education and higher education practice, with historical artefacts being recognised as powerful tools for promoting higher order thinking. German and Harris (2017) point to the 'agile' function of museum objects in encouraging students' engagement with a broad range of topics, from discipline-specific (material, history, use) to interdisciplinary (the same object could be explored from the point of view of anthropology, creative writing, history, microbiology), and even beyond the disciplines at the level of cross-disciplinary academic practice that underpins learning (interrogation, critical thinking). Hardie (2015) offers inspiring examples from her art and design practice, which promotes meaning making and experiential learning through interrogation of objects and images. Other accounts have also been provided around the value of special collections for cross-disciplinary pedagogies (Carini, 2016; Yaco et al., 2016). Chatterjee and Hannan (2015) provide a comprehensive overview of both theory and practice around object-based learning in higher education and its rich potential for helping students develop critical and abstract thinking, creativity, and research skills in a variety of disciplines, from art and design to biosciences, music and education.

There are multiple reasons behind these cross-disciplinary developments. The everchanging landscape of higher education drives institutions towards creativity and innovation through cross- and inter-disciplinary collaborations at the level of research, programmes and instruction (Jacob, 2015). Our main task as educators is, arguably, to provide our students with opportunities to prepare for what Brandt and Eagleman (2017) refer to as 'creativity economy', where 'the only thing that allows us to face these accelerating changes [is] cognitive flexibility[...] We absorb the raw materials of experience 
and manipulate them into something new [...] reaching beyond the facts [...] We master what is, and envisage what-ifs' (Brandt and Eagleman, 2017, p.8). In other words, there is an increasing value placed on developing the 'skill of transfer' (Gibbs, 2014, p.3), an 'adaptive expertise [...] where the context learning is intended to transfer into is new and different in important respects but where you nevertheless expect your graduates to cope better than others'. We want to equip our students with approaches and ways of thinking, which they can adapt and apply to a range of contexts and scenarios. Interdisciplinary instruction has the potential to support students in enhancing their higher order cognitive ability, including critical thinking, bias recognition and working with ambiguity (Vess and Linkon, 2001; Repko, 2007).

With this in mind, we see the flexibility of special collections as twofold. On one hand, special collections provide our students with an opportunity to practice cognitive flexibility and develop the skill of transferring creative solutions to unfamiliar contexts. Abstract thinking and critical analysis, imagination and creativity, reflection and learning transfer are central to both engaging with the discipline and graduate employability (Universities UK, 2015; UAL, 2018). On the other hand, the collections present themselves as a flexible resource, which can be adapted to suit a range of disciplines, topics and study levels.

Current literature on special collections draws on a range of pedagogical theory; there are strong connections with Kolb's (1984) experiential learning, multisensory learning (Morrison, 2015), curiosity, and museum-based learning (Vitelli, 2014; Chatterjee and Hannan, 2015; Hardie, 2015; German and Harris, 2017). We draw on this literature to suggest that well-established practices in museum and arts-based education, such as interrogating objects and images, meaning making and critical reflection, have potential to enhance mastery of important academic practices.

We also extend the understanding of special collections to flexible 'post-disciplinary' pedagogy (Ryan and Tilbury, 2013), whereby the artefacts are used to promote development of academic practices that not only underpin, but also go beyond the discipline, specifically: critical thinking, information literacy, questioning and positionality. These practices may present a challenge for both lecturers (to teach effectively) and students (to articulate, and to clearly demonstrate), as they rely on abstract (and 
subjective) processes that underpin learning (Johnston et al., 2011; Brown, 2014; Dunne, 2015).

The discourse around criticality, questioning and narrative construction as the foundation for engaging with historical artefacts, as well as their role in relation to the process of critical and aesthetic enquiry, are well developed in the museum education literature (see, for example, Raney, 1999; Bevan and Xanthoudaki, 2008; German and Harris, 2017) and slowly gaining momentum in teaching and learning development in higher education. Furthermore, the discourse around visual pedagogy and intertextuality (see, for example, Moss, 2010; Rifà-Valls, 2011) provides a useful frame of reference for our work, in which both visual and verbal language are approached as 'text'. In this sense, the language born out of the interaction between objects and images (and/or verbal text) can supply learners with meaningful contextualisation for their process of enquiry.

Indeed, it may at first seem counterintuitive to use sensory and visual methods as a way to connect with new knowledge within a text-centred discipline, while most of the academic processes and outputs gravitate currently towards text (see, for example, Raney, 1999; Chatterjee et al., 2015). Yet engaging with objects and images can make thinking, exploring, making connections, analysing and imagining - processes that are difficult to capture - tangible and more visible (see Dunne, 2015). It also fosters a dynamic learning environment, fuelled by excitement and curiosity - what Hardie (2015) refers to as 'the power of wow'. This type of innovative instruction can also be challenging; as Bateson (2001) puts it: 'at the centre of any tradition, it is easy to become blind to alternatives' (p.73).

In relation to interdisciplinarity specifically, there is evidence that interdisciplinary pedagogical methods can produce exciting results. For example, a study by Jasani and Saks (2013) illustrates how art can be used to help medical students develop observation skills in clinical diagnosis. Four themes identified in Jasani and Saks's analysis centre around subjective terminology, scope of interpretations, speculative thinking and use of visual analogies. So, by encouraging our students to consciously reflect on their 'ways of looking' and 'ways of seeing' objects and images from our special collections, we encourage our students to further develop their critical eye and skill of interpretation, and then find intertextual ways of transferring these approaches to the subject knowledge. 


\section{Special collections 'three ways'}

The collections utilised in the case studies are The Bedford Physical Education Archive (University of Bedfordshire, 2018) and The Bernarr Rainbow Collection at the UCL Institute of Education. We highlight the collections' versatility through applying three different frames: teaching and learning enhancement, information literacy and academic writing. We see the 'post-disciplinary' (Ryan and Tilbury, 2013) potential of special collections, as we work across and alongside specific disciplines in our professional roles.

\section{Our method}

Our method is a pedagogical approach grounded in object-based learning in museums and higher education (Chatterjee and Hannan, 2015; German and Harris, 2017). This article provides a snapshot in time of us exploring this method, as it is understood in artsbased disciplines, with discourse around deconstruction, necessary reiterations and outputs (see, for example, Nelson, 2013; Skains, 2018). Our exploration is ongoing, and this snapshot depicts our initial practitioner observations and experiences, and the process of adapting and refining our pedagogical method. Our process maps deconstruct the scaffolding of activities and processes in our sessions; our reiterations use archives across different disciplines, levels and topic areas; our output is our case studies.

The method needed to be adaptable in order to embed it into teaching across different disciplines, and at different levels of study. Two consistent methodological aspects have been the phased introduction of objects and the questioning technique, both used to encourage interaction, reflection-in-action, and reflection-on-action (Grushka et al., 2005). The explorative design was shared with the students from the start; the experimental, 'beyond-the-discipline' nature of the activity was explained in order to encourage active participation and to request verbal consent. Student feedback was collected at the end of each session, through post-it notes, around three themes: what went well, what did not, and what was surprising (in a couple of words). Post-its are an accessible tool, bringing further interactivity and allowing gathering of feedback without 
contributing to 'survey fatigue' (see, for example, Peterson and Barron, 2007). The nature of the feedback ensured brevity, anonymity and activity-specificity.

The themes arising from student responses provided insights in addition to our observations and feedback from academic peers at development workshops. The development workshops were initially delivered by two of the current authors; the third author of this paper participated in one of the workshops and subsequently collaborated with the two practitioners to develop and adapt the method to be trialled in each of our areas of practice. We co-designed the scaffolding and questioning techniques and the three feedback prompt questions for each session. After each session or 'iteration' we shared our own insights and those of our students. The insights from both peers and students, along with our own observations, helped inform our practice further, and we modified the method accordingly after each iteration. Student feedback was consistent with our own observations, and these insights and further steps for development are discussed in the 'reflections and observations' section. To illustrate the process of designing, refining and implementing the method, we developed the following concept map (Figure 1):

Figure 1. Process of Method Design

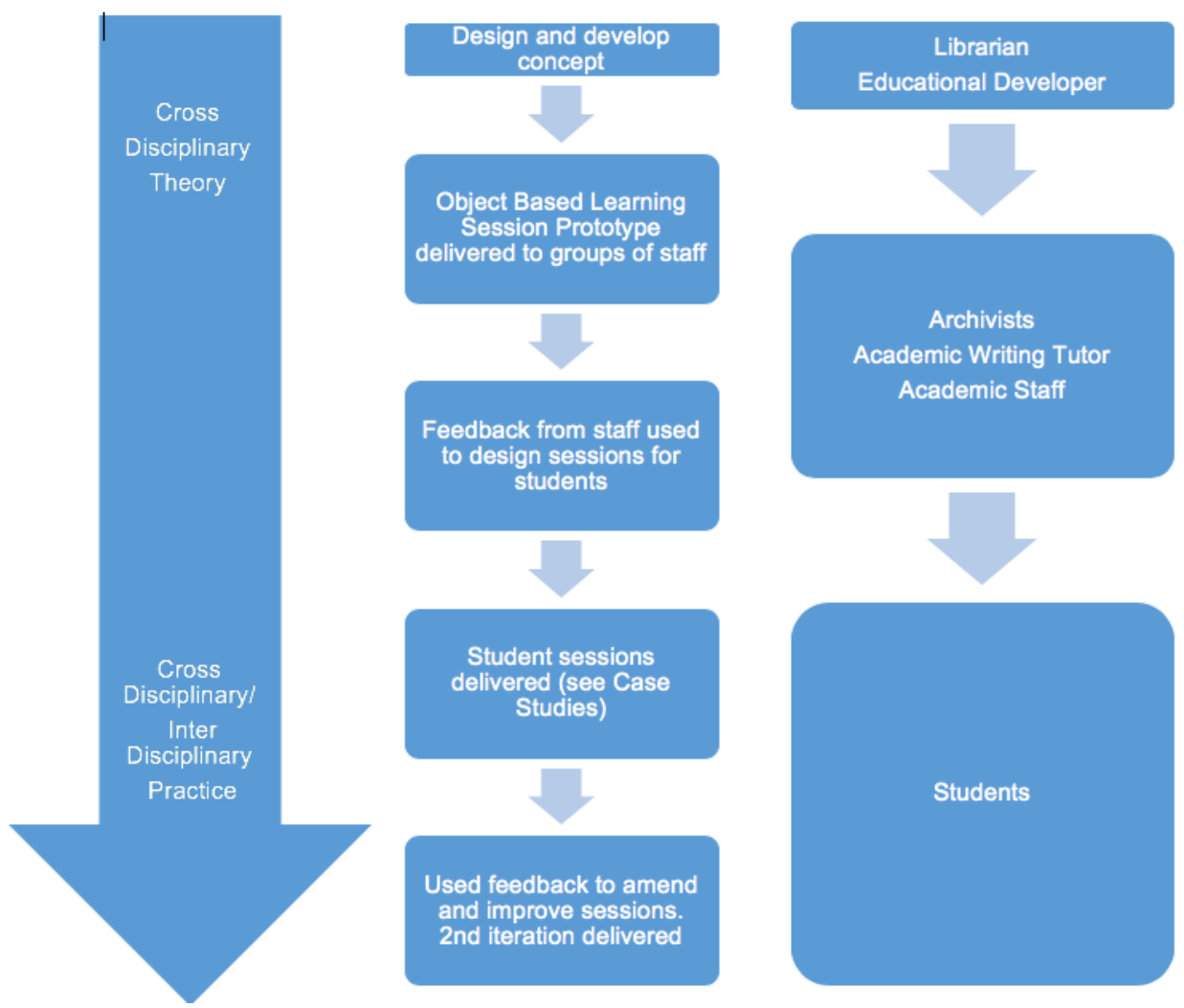


The process illustrated above is still ongoing. Below we share our initial experiences, observations and insights through three case studies - one from each of our specific practitioner perspectives.

\section{Case study 1: Using special collections to encourage questioning and narrative enquiry: an educational development perspective}

Focus on: questioning, narrative enquiry, subjectivity, positionality

As an educational developer, my interest was in 'trying out' the special collections approach for the purposes of discipline-specific teaching, in this case, in Education Studies. The method was offered to two groups of final year undergraduates (thirty students in each group, working in groups of five). The activity aimed to create a space for the participants to practice questioning techniques as a 'driver' for narrative enquiry, as part of preparation for their dissertation project.

The importance of questioning as a higher cognitive skill, and even as an 'art' has been highlighted in the literature (Doering and Pekarik, 1996; Phillips and Duke, 2001; Yang et al., 2005). The dialogical, critical and reflexive nature of questioning can be used to direct enquiry - not only into a topic, but also into the learner's own positionality (and how subjectivities may impact the narrative construction). Parallels with Socratic questioning and guided self-discovery can be made here (Paul and Elder, 2008). In particular, Mezirow's (2003) concept of 'communicative learning' is helpful, in which questioning encourages 'critique of the assertion itself' (p.8).

Formulating research questions and 'unpacking' the research topic is an area that students may find challenging (Anderson and Arsenault, 2005). The students were asked to create possible narratives around sets of artefacts: photographs, sports equipment, journals (see Process map 1). Starting with the artefacts that presented fewer potential cues (relatively abstract photographs), each following object could be more easily interpreted (a threedimensional object). The last object contained most identifiable information, including text (journals). 


\section{Process map 1. Special collections as a catalyst for questioning and narrative building (Bedford Physical Education Archive, University of Bedfordshire Special Collection).}

Step 1. Individual inquiry. In two minutes, write down twenty questions about the image
Reflection. Share questions with the group. What did you ask? Are there different / similar questions? Why did you ask this?

Step 3. Collaborative inquiry. A physical object is added to the set. Now, consider the three artefacts together. Go back to your initial questions. Can you answer any? Go back to your scenarios. What story is emerging? Does the new artefact confirm, or confuse your assumption? How? Why?

Reflection. How does your narrative look now? At which point did it start taking this shape? What helped you make that decision? Which questions were the most helpful? Which questions got answered? Which ones didn't?

Step 5. Final interpretations and narrative presentations.

Discussion: ways of seeing and questioning. Application for developing research questions and narrative construction.
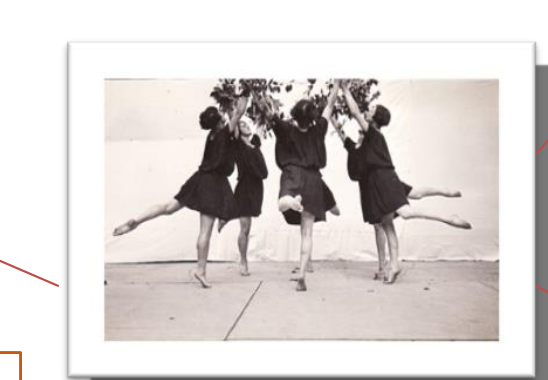

The first artefact contains very few cues - to encourage questioning and curiosity
Step 2. Collaborative inquiry. Another artefact added. Question and explore possible connections between the two photographs. What scenarios are emerging?
Reflection. How are you looking for clues? Where are you looking? Are you including everyone's perspectives? Are you dismissing some storylines? What still fits? What doesn't? What is missing? What are your facts, and what do you have to assume or imagine?
Step 4. Collaborative inquiry. The fourth object added, which contains more 'clues'. Keep developing the questions and the narratives. What story is emerging? Which artefact is central to your story? Why?
Reflection. What questions do you ask? What questions did others ask? What would you like to adapt? What do you pay attention to? What else is there? 
As "not all learning is "learning to do" but $[\ldots]$ understanding $[\ldots]$ the meaning of what others communicate' (Mezirow, 2003, p.204), it was made clear to the students that 'ways of seeing' and 'ways of knowing' would be encouraged (not only 'what?', but also 'what if?'). It was important to help the students connect with their individual creativity, thinking disposition and positionality - to elicit possible meanings, interpretations and narratives. The observed effect was a dynamic and collaborative process of iteration and reiteration, which manifested through 'layering' of interpretations, forming into narratives. Encouraging multiple reiterations promotes 'possibility thinking' and creates negotiated meanings (Dillon and Howe, 2003).

As the workshop was designed to support students' thinking around a possible dissertation topic, and the articulation of research questions, it was important to make sure this connection, and the transferability was not lost. The students were asked to identify aspects of questioning and narrative building, which could be used to 'interrogate' their chosen topic area, as well as to identify, and critique, their own positionality. The activity resulted in a variety of narratives and interpretations that comprised an amalgamation of the students' own experiences, imaginations, and factual information - addressing both the 'content' (breadth) and the 'meaning' (depth) (Polkinghorne, 2006).

Feedback from the students indicated that they found the activity engaging and enjoyable; the value of working with authentic artefacts was mentioned; the interaction with peers and sharing of analytical experiences was valuable; some students were positively surprised by their own creativity. Reflecting on the observation of students' interactions and engagement during the session and their feedback, the 'scaffolding' approach to 'layering' the information (by presenting the artefacts one after another; and encouraging reflection after each stage) seemed to support students in practising their metacognitive skills (see, for example, Holton and Clarke, 2006) and encouraged the process of collaborative enquiry. 


\section{Case study 2: Using special collections to encourage criticality: an information literacy perspective}

Focus on: critical thinking, information literacy, textual interrogation, argumentation

For librarians, communicating the value of information literacy as a lifelong research skill is a challenge due to the fleeting nature of our contact with the students. The demonstration of practical research skills is an established practice, but this does not necessarily lead to better equipped students (Walsh, 2018). Using objects to scaffold this learning, as ArnoldFoster et al. (2015) discuss, is a way for librarians to be further involved in the development of students, for them to impart 'skills of transfer' (p.3) in a memorable and engaging way, utilising the active learning pedagogical approach (Gibbs, 2014).

'Information literacy' is defined as 'the ability to think critically and make balanced judgements about any information we find and use' (CILIP, 2018). The artefacts used in this session were similar to Case Study 1 ; by using objects that were not immediately related to their subject, students could question and critically evaluate information whilst demonstrating their 'intellectual humility' (ACRL, 2016, p.7) - they acknowledge their own experience may lead to limitations, but remain open minded to other perspectives and interpretations.

The session was offered to three groups of around 30 Foundation Year Business students (level three), split into groups of between three and five, and the aim was to encourage them to develop the skills they require to thrive during undergraduate study (see $Q A A$, 2014, level descriptors). The workshop helped to identify a process of establishing common themes and presenting a summary argument - vital for undergraduate study (Van Gelder, 2015). The session required students to interpret the artefacts and make links between them, before repeating the process with academic resources (see Process Map 2). As discussed above, the historical artefacts were not specific to the students' own discipline. The academic sources that students would be expected to utilise (for example journal articles), were all subject-related and this allowed us to observe whether students were able to transfer the processes and skills in which they engaged when exploring the objects to discipline-specific enquiry. 
The groups seemed initially cautious but became more engaged with the objects through the scaffolding of the questioning processes and explorative activities, echoing the ACRL framework, which values 'developing [...] new investigative methods' (ACRL, 2016, p.7) and encourages students to have an open mind, criticality, flexibility and creativity (ACRL, 2016). All students started from an assumed 'level playing field' (since the objects were unfamiliar and not immediately related to the specific discipline), which encouraged them to draw on their own backgrounds and skills to interpret the information.

During the contextualisation stage, in which students moved to evaluating academic sources, skilful facilitation was needed in order to explain how the processes engaged in when exploring the artefacts could be transferred. This aspect of our method may be challenging for the facilitator to navigate - it was important to keep reminding the students that they should avoid focusing narrowly on the specifics, and instead focus on themes. This challenge enabled an unscheduled but frank discussion about how to strategically read literature.

The initial questioning activity was useful, and some students did grasp that they were learning lifelong skills. The limitations of the session from the student perspective, as evidenced in their feedback, were the length of time in which to read the literature when using subject material, repetitiveness of the task cycle, and a perception of lack of relevance to their subject or assignment work. Overall, though, the feedback was positive, and the atmosphere in the room was energetic, demonstrating that students seemed to enjoy learning through a new and innovative technique - this was also explicitly stated in their feedback. 


\section{Process map 2: Special Collections as a catalyst for critical enquiry and information literacy (credit: Bedford Physical Education Archive, University of Bedfordshire Special Collection)}

Step 1. Students split into
groups of three and handed
one photograph. Write down
20 questions about the photo
in 2 minutes.

ACRL guidelines: information literate persons can "formulate questions for research based on information gaps or re-

examination of existing, possibly conflicting, information" (ACRL, 2016, p. 7)

Step 3. Additional artefacts were added, one at a time, every 3-4 minutes. Groups asked to think if the questions they generated could be applied to the additional objects, and if they could identify common themes.

ACRL: draw conclusions based on analysis and interpretation of information (ACRL, 2016, p. 7)
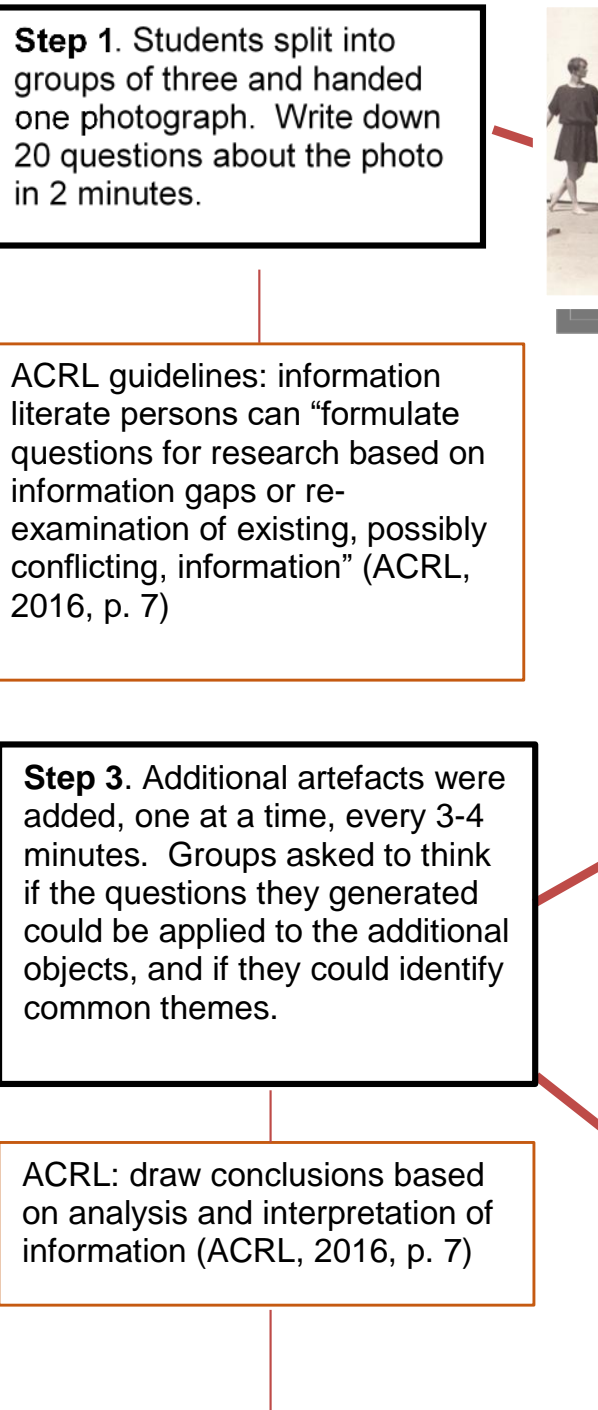

The sources were a journal article, news article, government legislation all themed around workplace policy on uniforms, which added both academic and subject context.

\footnotetext{
Step 5 . The process was
repeated, but with academic sources.
}

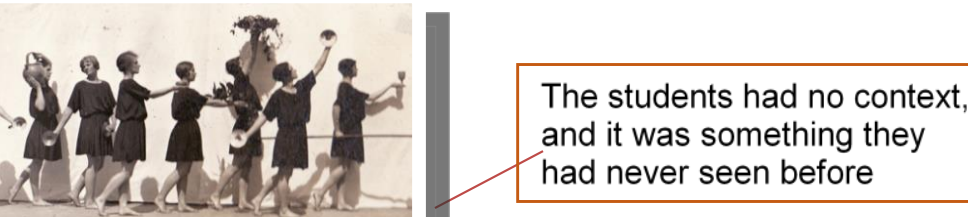
and it was something they had never seen before had never seen before

Step 2. Groups discussed their questions. Were they the same or different? Why?

ACRL: Intellectual curiosity, mental flexibility, open mind and critical stance (ACRL, 2016)

SCONUL: evaluate (SCONUL, 2011)

ANCIL: Critical analysis, textual interrogation, finding your voice (Secker and Coonan, 2011)

Argument Mapping: identify the main argument, link to other texts, critical thinking improvement (van Gelder, 2015)

Step 4. Groups reported their objects and conclusions to the class. Skills used identified and discussed.

Step 6. Students were asked to reflect on what they had learned, and complete informal post it feedback. 
It can be argued that information literacy is a basic human right, as it enables and empowers (IFLA, 2015). An activity that incorporates artefacts can address the challenges of teaching one-off sessions by making the content and the meaning more memorable and emphasising the transferability of research skills and critical thinking. This method helps students to view research skills as something beyond their curriculum - as a 'postdisciplinary' (Ryan and Tilbury, 2013) transferable competency, rather than just a set of processes that they can learn to enhance their academic progression.

\section{Case study 3: Special collections as a catalyst for criticality and creativity in reviewing literature: an academic writing perspective}

\section{Focus on: literature review, criticality, academic writing}

In academic writing development, genre and text analysis are common pedagogical approaches (see, for example, Wingate, 2012); however, writing processes are often abstract, tacit and 'opaque' (Gourlay, 2009). We therefore sought to 'awaken' some of the possible processes involved in critically reviewing literature using historical artefacts from the Bernarr Rainbow Special Collection at the UCL Institute of Education Library.

Two workshops were developed by the Special Collections Librarian and Senior Teaching Fellow in Academic Writing for postgraduate Music Education students - one in 2017 (20 participants), and one in 2018 (25 participants) which was a revised repeat of the earlier workshop, based on collaborative reflections with the authors of this paper and feedback received on the earlier 'iteration'. In the earlier iteration, student feedback revealed that some of the instructions during the scaffolding of the activities may have been unclear, and it was important to clarify the non-prescriptive and interpretative approach to exploring the objects and their possible connections. Student feedback also indicated that more time devoted to the 'transfer' reading and writing activities would have been beneficial, and timings were therefore also adapted. The activities and stages of the session can be seen in Process Map 3 below. 


\section{Process map 3: Special Collections as a catalyst for criticality and creativity in} reviewing literature (credit: Bernarr Rainbow Collection, UCL Institute of Education

\section{Library)}

Step 1. Individual inquiry with an initial image artefact. In two minutes, write down twenty questions about the image.

Reflection. Share questions with the group. Are questions similar or different? What do they say about your educational / professional background and your biases?

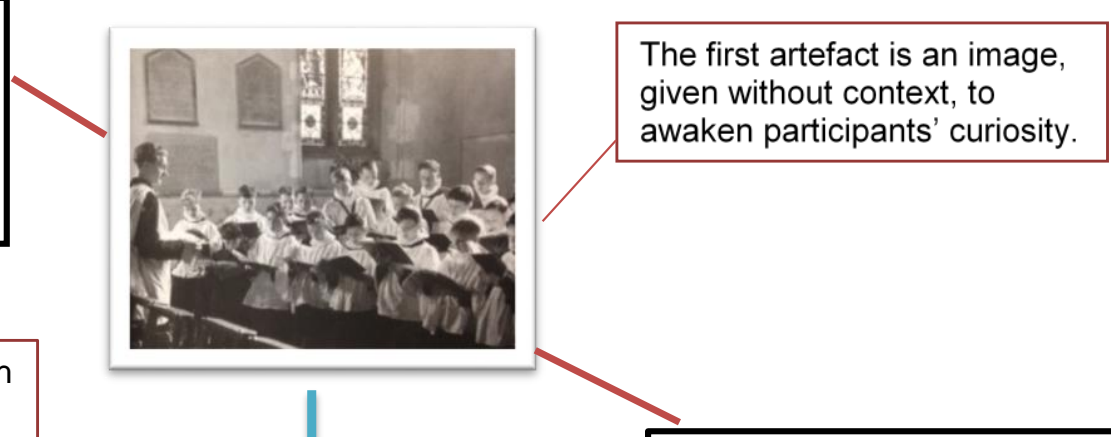
The first artefact is an image, Step 2. Collaborative inquiry and further exploration. Additional images and physical artefacts added. Each table is given a group of artefacts these are grouped together by theme (e.g. teaching singing using handsigns, boys choirs, conversational teaching, foundations of music etc.). Step 3. Collaborative enquiry and 'Detective work' (Hardie, 2015). How might all the artefacts piece together? Can there be more than one interpretation? What is missing to help you make connections, disconnections and draw conclusions? Where are the 'silences'? What is not being said. What is missing? What do you still want to know and why?

Group discussion and reflection on group interpretations.

Followed up with 'revealing' of origin of artefacts.

Step 5. Reflection on the processes engaged in during the previous steps. What processes/ senses were 'awakened' when exploring the artefacts? Which verbs / action phrases could be used to describe the processes you engaged in during the task? (e.g. analysing, evaluating, synthesising, delving)
Participants are encouraged to explore connections between artefacts and to the initial image, in order to ignite the 'research imagination' (Hart, 1998).
Step 4. Present one

interpretation of the artefacts per group (2 minutes).

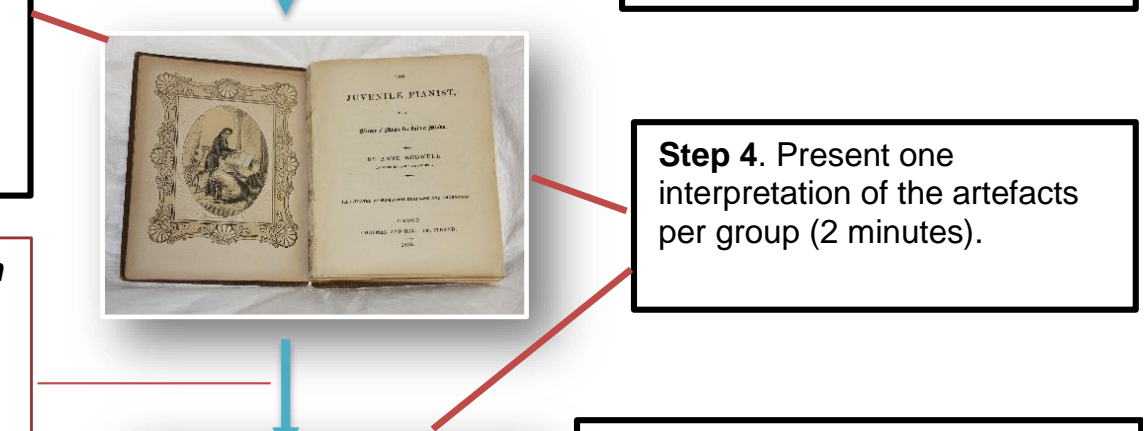

Step 6. Linking and application to literature review research and writing processes. How do the processes identified in Step 5 relate to process of researching and reviewing literature? What is the value of historical inquiry in the processes of academic researching and writing? How are these processes identified in your reading? How can they be demonstrated in your writing? 
The artefacts included images representing the history of music education and historical texts on music education and pedagogy. Each group was given an initial image to examine individually before the phased introduction of additional images to explore and discuss as a group. The aim was to simulate some of the questioning processes involved in critically reviewing literature and activate the participants' own meaning-making and creative processes in order to ignite the 'research imagination' (Hart, 1998). The activity concluded with participants presenting a summary of their interpretation of the artefacts.

In the post-task reflection, participants discussed how criticality might be demonstrated in researching and reviewing literature: situating themselves and thereby foregrounding their own voices and experiences, going beyond describing what is said in the literature, synthesising ideas and perspectives, making new meanings, considering new options that remain under the surface. For example, one group noted that their questions on the initial artefact corresponded with their professional backgrounds and research interests (see Process map 3); some of the participants had questions about the pedagogical approaches to music being depicted, whilst others discussed social indicators such as dress and gender.

Based on our observations during the session and students' verbal and written responses, the historical artefacts awakened the learners' curiosity in a unique way partly because of the 'unfamiliarity' of the objects - the opportunity to 'play detective' was highlighted in student feedback, and students were able to draw parallels with the research and reviewing process. There was a 'buzz' around the room as artefacts were revealed, and the associated connections, disconnections and silences were explored (Hardie, 2015). Using artefacts in this way, underpinned by principles of object-based learning (Robyns, 2001; Carini, 2016), also helped to develop students' critical information literacies by considering questions about what the object was, when and why it was created, and how it was used or could be used in the present time, taking into consideration the wider contexts. Thus, students were constructing knowledge through their experiences of exploring (unfamiliar) objects (Chatterjee et al., 2015), which, we argue, simulates some of the possible processes involved in critically reviewing literature. 
Our case study highlights the pedagogical value of historical artefacts beyond disciplinary learning and how they could be used to activate processes of critical enquiry, synthesis, independent thought, meaning making and creativity. For academic writing development specifically, we observed the potential of exploring abstract concepts and processes through interdisciplinary and post-disciplinary means alongside traditional text-based approaches. As discussed above, exploration of the objects seemed to help make these concepts more tangible and highlight the underpinning 'discovery' nature of literature reviewing. Exploring these concepts and processes in practical ways that illuminate criticality, creativity and meaning making preceding the written 'end product', may help to reinforce the idea that creating and constructing knowledge is a core purpose of academic writing.

\section{Outcomes, reflections and lessons learnt}

Our case studies serve as a snapshot of how a pedagogical method can be designed and explored through application, with peers and students, to inform further development. Our main aim was to explore - through our own practitioner observations and informal student feedback - whether and how interaction with historical artefacts can support students in engaging with the topic material, through a method that seemingly sits outside the immediate disciplinary boundaries.

Our work highlights the flexible nature of special collections as a pedagogical resource, adaptable for a range of disciplines, levels and learning outcomes. The artefacts acted as a catalyst for participants' curiosity, reflexivity and sense of subjectivity; the unusual nature of the images and objects and the method of working with them was mentioned as something memorable, surprising, as a positive feature of the workshop ('something different').

Our examples are in no way definitive or exhaustive in terms of the potential of special collections. What our experiences and observations showed, however, is that careful planning and 'dynamic teaching' (Chatterjee and Hannan, 2015) play a vital role in the successful running of a workshop that incorporates special collections. Indeed, in order for the students to harness the 'skills of transfer', we need to make visible the import of the transferable characteristics between contexts, so that 'the intellectual and practical 
processes involved are pretty much the same' (Gibbs, 2014, p.2). We observed that the artefacts can make the process of exploration more visible and tangible; it is important to encourage students to notice what they have just done, and how. Once that process of own enquiry is captured and visualised, it can then be deconstructed and re-applied to the context of the subject-related task. This was evidenced when students were required to transfer processes and skills used in exploring the objects to a discipline-specific text/writing-based task; we observed that students were able to 'replicate', amend and apply the processes and skills to fit the target context within the sessions.

'Layering' the questions and instructions in stages and allowing time for reflection are key (see process maps). If time is limited, fewer elements of the presented activities may be used. Another observation was that students at the start of their academic journey may benefit from more detailed instruction, while higher level students will be more selfdirected.

It is important to clarify that we argue for the pedagogical value of special collections based on our initial observations, experiences and informal student feedback. In the next stage of our exploration, we will look to explicate this value through further longitudinal exploration of how students apply what is learnt through interrogating artefacts to further discipline-specific learning. Based on our initial exploration, we would like to echo the words of Roth (2014) and Vitelli (2014), and suggest that special collections can and should be like libraries: accessible to students and supporting their learning.

\section{References}

ACRL (2016) Framework for information literacy in higher education. Available at: http://www.ala.org/acrl/sites/ala.org.acrl/files/content/issues/infolit/Framework ILHE. pdf (Accessed: 19 June 2019).

Anderson, G. and Arsenault, N. (2005) Fundamentals of educational research. $2^{\text {nd }}$ edn. London: Routledge. 
Arnold-Foster, K., Reynolds, R. and Smith, R. (2015) 'Co-developing a scaffolding structure for doctoral collections-based research at the University of Reading', in Chatterjee, H. and Hannan, L. (eds.) Engaging the senses: object-based learning in higher education. London: Routledge, pp.159-176.

Bateson, M. (2001) Composing a life. New York, NY: Grove Press.

Bevan, B. and Xanthoudaki, M. (2008) 'professional development for museum educators: unpinning the underpinnings', The Journal of Museum Education, 33, pp.107-119.

Brandt, A. and Eagleman, D. (2017) The runaway species: how human creativity remakes the world. Edinburgh: Canongate Books.

Brown, A. (2014) 'How students make sense of criticality skills in higher education', Practitioner Research in Higher Education, 9(1), pp.4-17.

Carini, P. (2016) 'Information literacy for archives and special collections: defining outcomes', Portal: Libraries and the Academy, 16(1), pp.191-206.

Chatterjee, H. and Hannan, L. (eds.). (2015) engaging the senses: object-based learning in higher education. London: Routledge.

Chatterjee, H., Hannan, L. and Thomson, L. (2015) 'An introduction to object-based learning and multisensory engagement', in Chatterjee, H. and Hannan, L. (eds.) Engaging the senses: object-based learning in higher education. London: Routledge, pp.1-18.

CILIP (2018) CILIP definition of information literacy 2018. Available at: https://infolit.org.uk/definitions-models/ (Accessed: 19 June 2019).

Dillon, P. and Howe, T. (2003) 'Design as narrative: objects, stories and negotiated meanings', The International Journal of Art and Design, 22(3), pp.289-296. 
Doering, Z. and Pekarik, Z. (1996) 'Questioning the entrance narrative', The Journal of Museum Education, 21(3), pp.20-23.

Dunne, G. (2015) 'Beyond critical thinking to critical being: criticality in higher education and life', International Journal of Educational Research, 71, pp.86-99.

German, S. and Harris, J. (2017) 'Agile objects', Journal of Museum Education, 42(3), pp.248-257.

Gibbs, G. (2014) 53 powerful ideas all teachers should know about: transferable skills rarely transfer (Idea Number 3, May 2014). Available at: https://www.seda.ac.uk/resources/files/publications 147 3\%20Transferable\%20skill s\%20rarely\%20transfer.pdf (Accessed: 17 December 2018)

Gourlay, L. (2009) 'Threshold practices: becoming a student through academic literacies', London Review of Education, 7(2), pp.181-192.

Grushka, K., Hinde-McLeod, J. and Reynolds, R. (2005) 'Reflecting upon reflection: theory and practice in one Australian university teacher education program', Reflective Practice, 6(1), pp.239-246.

Hardie, K. (2015) Wow: The power of objects in object-based learning and teaching. Available at: https://www.heacademy.ac.uk/system/files/kirsten hardie final.pdf (Accessed: 17 December 2018).

Hart, C. (1998) Doing a literature review: releasing the social science imagination. London: SAGE.

Holton, D. and Clarke, D. (2006) 'Scaffolding and metacognition', International Journal of Mathematical Education in Science and Technology, 37(2), pp.127-143.

IFLA (2015) Beacons of the information society: The Alexandria Proclamation on information literacy and lifelong learning. Available at: 


\section{https://www.ifla.org/publications/beacons-of-the-information-society-the-alexandria-} proclamation-on-information-literacy (Accessed: 19 June 2019).

Jacob, W. (2015) 'Interdisciplinary trends in higher education', Palgrave Communications, 1 (15001).

Jasani, S. and Saks, N. (2013) 'Utilizing visual art to enhance the clinical observation skills of medical students', Medical Teacher, 35(7), pp.1327-1331.

Johnston, B., Ford, P., Mitchell, R. and Myles, F. (2011) developing student criticality in higher education: undergraduate learning in the arts and social sciences. London: Continuum International Publishing Group.

Kolb, D. (1984) Experiential learning: experience as the source of learning and development. Englewood Cliffs, NJ: Prentice Hall

Mezirow, J. (2003) 'How critical reflection triggers transformative learning', in Jarvis, P. and Griffin, C. (eds.) Adult and continuing education: major themes in education, Vol. IV Teaching Learning Research. London: Routledge, pp.199-214.

Morrison, E. (2015) 'Immersive and somatic learning: a summary of creative-based practice as a method for higher education', in Chatterjee, H. and Hannan, L. (eds.) Engaging the Senses: Object-Based Learning in Higher Education. London: Routledge, pp.207-224.

Moss, J. (2010) 'Understanding visual and intertextual approaches in pedagogical and curriculum research: a pretext', International Journal of Inclusive Education, 15(4), pp.379-388.

Nelson, R. (2013) Practice as research in the arts: principles, protocols, pedagogies, resistances. London: Palgrave Macmillan

Paul, R. and Elder, L. (2008) 'Critical thinking: the art of Socratic questioning, Part III', Journal of Developmental Education, 31(3), pp.34-35. 
Peterson, E. and Barron, K. A. (2007) 'How to get focus groups talking: new ideas that will stick', International Journal of Qualitative Methods, 6(3), pp.140-144.

Phillips N. and Duke M. (2001) 'The questioning skills of clinical teachers and preceptors: a comparative study', Journal of Advanced Nursing, 33(4), pp.523-529.

Polkinghorne, D. (2006) 'Narrative configuration in qualitative analysis', International Journal of Qualitative Studies in Education, 8(1), pp.5-23.

QAA (2014) UK quality code for higher education. Available at: https://www.qaa.ac.uk/quality-code (Accessed: 19 June 2019).

Raney, K. (1999) 'Visual literacy and the art curriculum', Journal of Art \& Design Education, 18(1), pp.41-48.

Repko, A. F. (2007) 'Interdisciplinary curriculum design', Academic Exchange Quarterly, 11(1). Available at:

https://go.galegroup.com/ps/anonymous?id=GALE\%7CA165912657\&sid=googleSc holar\&v=2.1 \&it=r\&linkaccess=abs\&issn=10961453\&p=AONE\&sw=w (Accessed: 19 June 2019).

Rifà-Valls, M. (2011) 'Experimenting with visual storytelling in students' portfolios: narratives of visual pedagogy for pre-service teacher education', The International Journal of Art and Design Education, 30(2), pp.293-306.

Robyns, M. (2001) 'The archivist as educator: integrating critical thinking skills into historical research methods instruction', The American Archivist, 64(2), pp.363-384.

Roth, M. (2014). 'Ukiyo-e to emoji: museums and the digital age', Digital Humanities Summer School, Oxford, UK, July. Available at: http://podcasts.ox.ac.uk/ukiyo-eemoji-museums-digital-age (Accessed: 19 June 2019). 
Ryan, A. and Tilbury, D. (2013) Flexible pedagogies: new pedagogical ideas. Available at: https://www.heacademy.ac.uk/system/files/resources/npi report.pdf (Accessed: 19 June 2019).

SCONUL (2011) The SCONUL seven pillars of information literacy core model for higher education. Available at:

https://www.sconul.ac.uk/sites/default/files/documents/coremodel.pdf (Accessed: 19 June 2019).

Secker, J. and Coonan, E. (2011) A new curriculum for information literacy. Available at: http://www.dspace.cam.ac.uk/handle/1810/244638 (Accessed: 19 June 2019).

Skains, R. L. (2018) 'Creative practice as research: discourse on methodology', Media Practice and Education, 19(1), pp.82-97.

UAL (2018) Creative attributes framework. Available at: http://www.arts.ac.uk/aboutual/teaching-and-learning/careers-and-employability/creative-attributes-framework/ (Accessed: 19 June 2019).

Universities UK (2015) Higher education in England: provision, skills and graduates.

Available at: https://www.universitiesuk.ac.uk/policy-and-

analysis/reports/Documents/2016/higher-education-in-england-provision-skills-andgraduates.pdf (Accessed: 19 June 2019).

University of Bedfordshire (2018) Bedford Physical Education Archive. Online. https://archiveshub.jisc.ac.uk/search/archives/87ba2990-92fe-3183-82502d8f7d6ff976 (Accessed: 12 December 2018).

Van Gelder, T. (2015) 'Using argument mapping to improve critical thinking skills', in Davies, M. and Barnett, R. (eds.) The Palgrave handbook of critical thinking in higher education, New York, NY: Palgrave Macmillan, pp.183-192.

Vess, D. and Linkon, S. (2001) 'Navigating the interdisciplinary archipelago: the scholarship of interdisciplinary teaching and learning', in Huber, M. T. and Morreale, 
S. P. (eds.) Disciplinary styles in the scholarship of teaching and learning: exploring common ground, Washington, DC: AAHE/Carnegie Foundation for the Advancement of Teaching, pp.87-106.

Vitelli, G. (2014) 'Thinking with objects: the Ashmolean museum's university engagement programme in the Oxford academic community', in Jandl, S. S. and Gold, M. S. (eds.) A Handbook for Academic Museums: Vol. 3, Cambridge, MA: MuseumEtc, pp.65-81.

Walsh, A. (2018) The librarian's book on teaching through games and play. Estonia: Innovative Libraries.

Wingate, U. (2012) 'Using academic literacies and genre-based models for academic writing instruction', Journal of English for Academic Purposes, 11(1), pp.26-37.

Yaco, S., Brown, C. and Konrad, L. (2016) 'Linking special collections to classrooms: a curriculum-to-collection crosswalk', The American Archivist, 79(2), pp.417-437

Yang Y., Newby T. and Bill R. (2005) 'Using Socratic questioning to promote critical thinking skills through asynchronous discussion forums in distance learning environments', American Journal of Distance Education, 19(3), pp.163-181.

\section{Author details}

Maria Kukhareva is the Head of Organisational Development at the Centre for Learning Excellence, University of Bedfordshire.

Anne Lawrence is an Academic Librarian and Space Manager at the University of East Anglia.

Katherine Koulle is a Senior Teaching Fellow at the UCL Institute of Education Academic Writing Centre.

Nazlin Bhimani is the Research Support \& Special Collections Librarian at the UCL Institute of Education. 